\title{
Magnetotelluric characterization of the Alhama de Murcia Fault (Eastern Betics): preliminary results
}

Anna Martí ${ }^{1}$, Pilar Queralt ${ }^{1}$, Juan José Ledo $^{1}$, Alejandro Marcuello ${ }^{1}$, Julen AlvarezAramberri $^{2}$ and José Jesús Martínez Díaz ${ }^{3}$

\footnotetext{
${ }^{1}$ Institut Geomodels, Departament de Geodinàmica i Geofísica, Facultat de Geologia, Universitat de Barcelona, 08028 Barcelona, Spain

${ }^{2}$ BCAM - Basque Center for Applied Mathematics, 48009 Bilbao, Spain

${ }^{3}$ Departamento de Geodinámica, Facultad de Ciencias Geológicas, Universidad Complutense, 28040 Madrid, Spain
}

\section{Introduction}

The Lorca Earthquake (11/5/2011, Mw 5.2) stands as the most destructive in Spain over the last 50 years. It was interpreted as having occurred in an intersegment zone of the strike-slip Alhama de Murcia Fault (AMF). Within the research project "Intergeosima”, a multi parametric characterization and monitoring of the fault structure is ongoing, with the aim of developing a future Near Fault Observatory (NFO) to improve the understanding of the seismic behaviour of the fault in the short and medium term. In this work we present the preliminary results of a magnetotelluric (MT) survey carried out along the rambla de la Torrecilla (SW of Lorca), which will allow characterization of the electrical resistivity of the AMF, constraining and complementing the knowledge obtained from the borehole that was drilled in the area, and to extend the geological interpretation of the fault gauge towards the SE.

\section{Geodynamic and geophysical settings}

The AMF is a left lateral strike-slip fault located at the eastern part of the Betics Internal zone (figure 1), composed of Paleozoic, Mesozoic and Paleogene rocks developed as a thrust stack during the Alpine orogeny. The major tectonic complexes (Nevado-Filábride, Alpujárride and Maláguide) were later reactivated through low-angle normal faults subject to regional extensional tectonics. In the neotectonic period (the last $9 \mathrm{My}$ ) a compressional stress field with a NNW-SSE direction became dominant and high-angle faults such as the AMF were formed, which have been active since Late Miocene (Martínez-Diaz et al 2012). Most of the damaging historical earthquakes ( $\mathrm{Mw}>6.5$ ) are related to the structure of the AMf (figure 1). The Lorca Mw 5.22011 earthquake was generated by the reactivation of a small section of this fault.

The project INTERGEOSIMA aims to identify and understand the structure and seismogenic behaviour of the AMF. The 3D structure is currently being characterised through the use of LIDAR, ERT, reflection seismics and MT. In order to perform a rheological analysis of the fault gauge, a borehole (FAM-1) was drilled $(174 \mathrm{~m})$ in the shear zone with the highest exhumation (rambla de la Torrecilla, $3 \mathrm{~km} \mathrm{SW}$ of Lorca, figure 2), and several trenches were excavated to determine the detailed structure of the fault zone. A preliminary geological interpretation (figure 2) shows that the fault gouge has a minimum width of $150 \mathrm{~m}$ with a $70^{\circ} \mathrm{NW}$ dipping. From NW to SE the observed units are graphitic schists from the Alpujárride complex, a clay rich fault gouge containing graphite, a melange of blue-gray phyllite fault gauge with Miocene marls, Miocene sandstones and Quaternary alluvial limes and gravels. In order to better constrain this interpretation and to obtain more information on the structure under the Quaternary deposits, an MT survey was carried out. Other MT studies for fault characterization had been performed in the Carboneras Fault, also in the Eastern Betics (Moreno et al., 2007). 


\section{Magnetotelluric Survey}

MT data were acquired across the AMF at 15 stations (figure 1), along the Rambla de la Torrecilla (SW of Lorca). Sites 7 and 8 delimit the survey to the WNW and are located over the Sierra de las Estancias (Alpujárride complex, Internal Betics). Sites 10 and 1 are located over the fault gauge (figure 2). The rest of sites were installed on top of Quaternary deposits.

Time series were recorded using ADU06 and ADU07 Metronix systems, measuring horizontal electric and magnetic fields at different sampling rates, with a total duration between $2 \mathrm{~h}$ and $18 \mathrm{~h}$, depending on the site. Given the short distance between sites $(200 \mathrm{~m})$, some pairs of stations were recorded simultaneously, with magnetic sensors in only one of them. The location of the survey is very close to the highway and an industrial zone, hence the time series can be highly affected by noise. In order to mitigate this effect, some sites were recorded over night, where anthropogenic activity is lower and to get enough samples and better statistics for the data processing. The contact resistivity between the electrodes and the soil presented high values, due to the low compaction of the terrain.

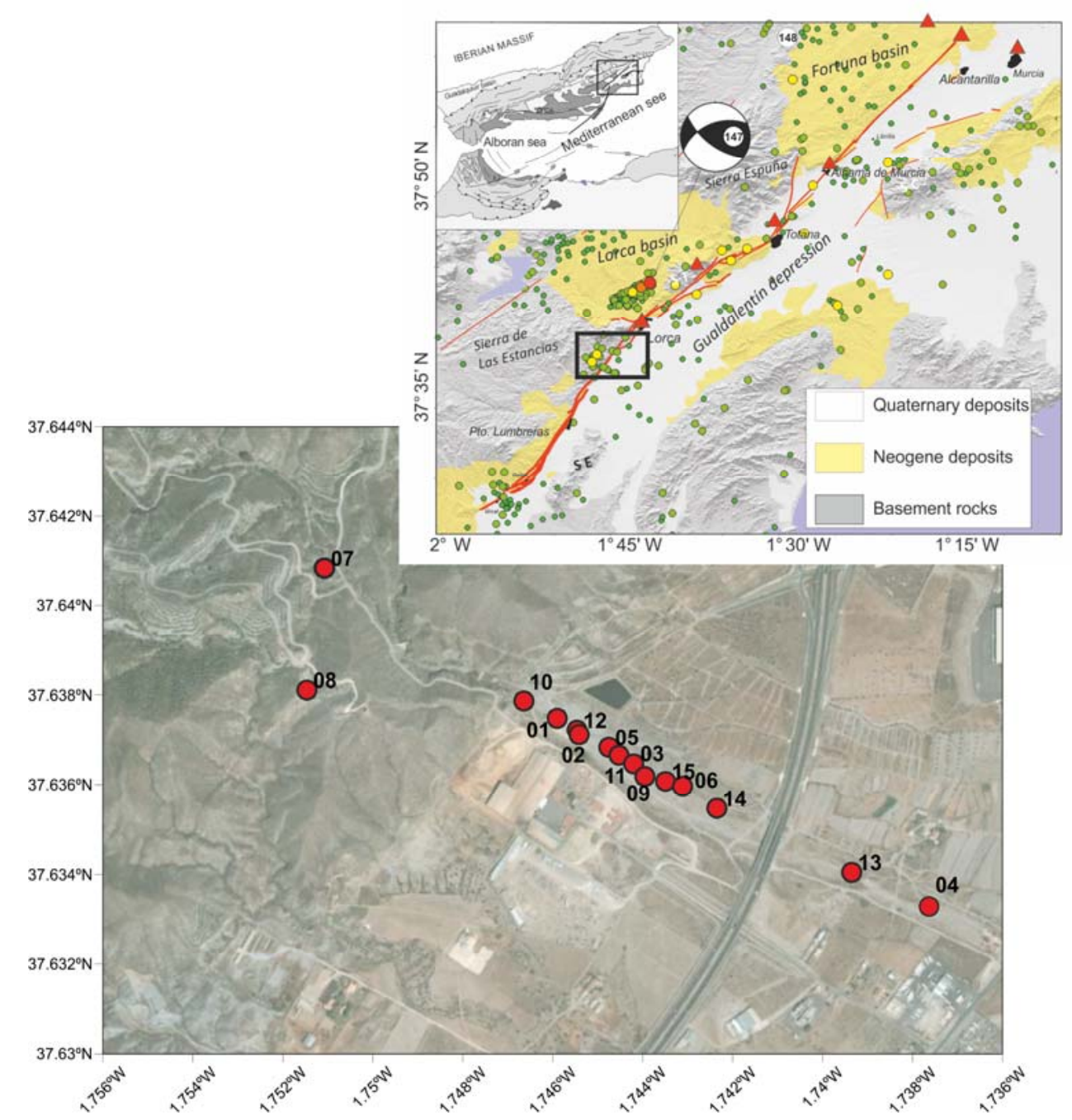

Figure 1 Top: Inset and geological map of the Alhama de Murcia fault (red) and epicentres of shallow historical earthquakes (circles) and damaging historical ones (red triangles). Mw 5.2 Lorca earthquake focal mechanism is represented. Labels 147 and 148 indicate the location of long period MT data previously acquired in the Sierra de las Estancias. Black rectangle limits the survey area of this study (modified from Martínez-Díaz et al. 2016). Bottom: Aerial view of the rambla de la Torrecilla area and location of the MT sites. 

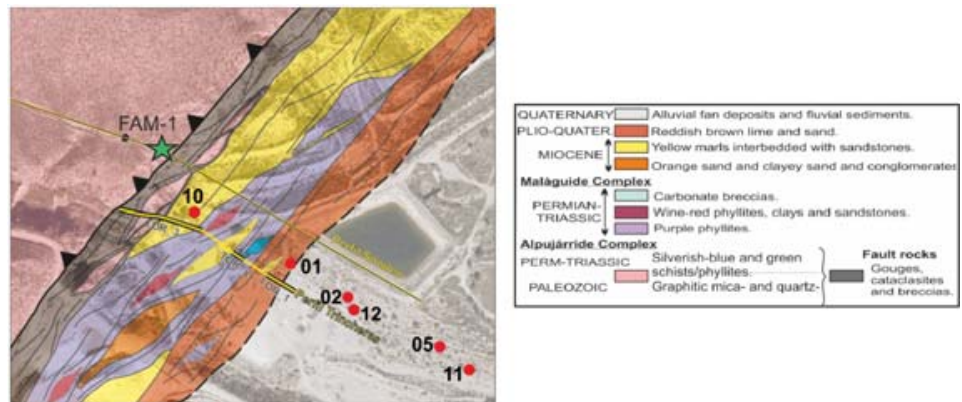

Figure 2: Geological map of the AMF fault zone and location of the central MT sites and the borehole FAM-1 (modified from Martínez-Díaz et al. 2016).

Time series were processed using Mapros and MTproc Metronix software based on a robust method. Data with poor quality were removed and the resulting transfer functions correspond to a period range between $10^{-3} \mathrm{~s}$ and $1 \mathrm{~s}$ to $10 \mathrm{~s}$ (and $100 \mathrm{~s}$ at some sites). A more detailed inspection and filtering of the time series at some of the recorded bands will allow improving the quality of these data.

\section{Preliminary results}

We show preliminary results from a selection of sites located on the central part of the survey. Dimensionality analysis was performed using the WALDIM1.1 (Martí et al. 2009) and Strike (McNeice and Jones 2001) programs. WALDIM analysis (figure 3) shows a general 3D behaviour of the data at all frequencies, with some 1D and 2D cases at the shortest periods. The few 2D cases have a strike between $32^{\circ}$ and $65^{\circ}$. Strike code analysis performed for all sites and periods shows a poor fit between the data and a 2D structure. However, this 3D behaviour seems to be an effect of noise, given that the geological structure has a clear NE-SW strike. A new analysis fixing the strike direction to $45^{\circ}$ resulted in a similar value of the misfit.

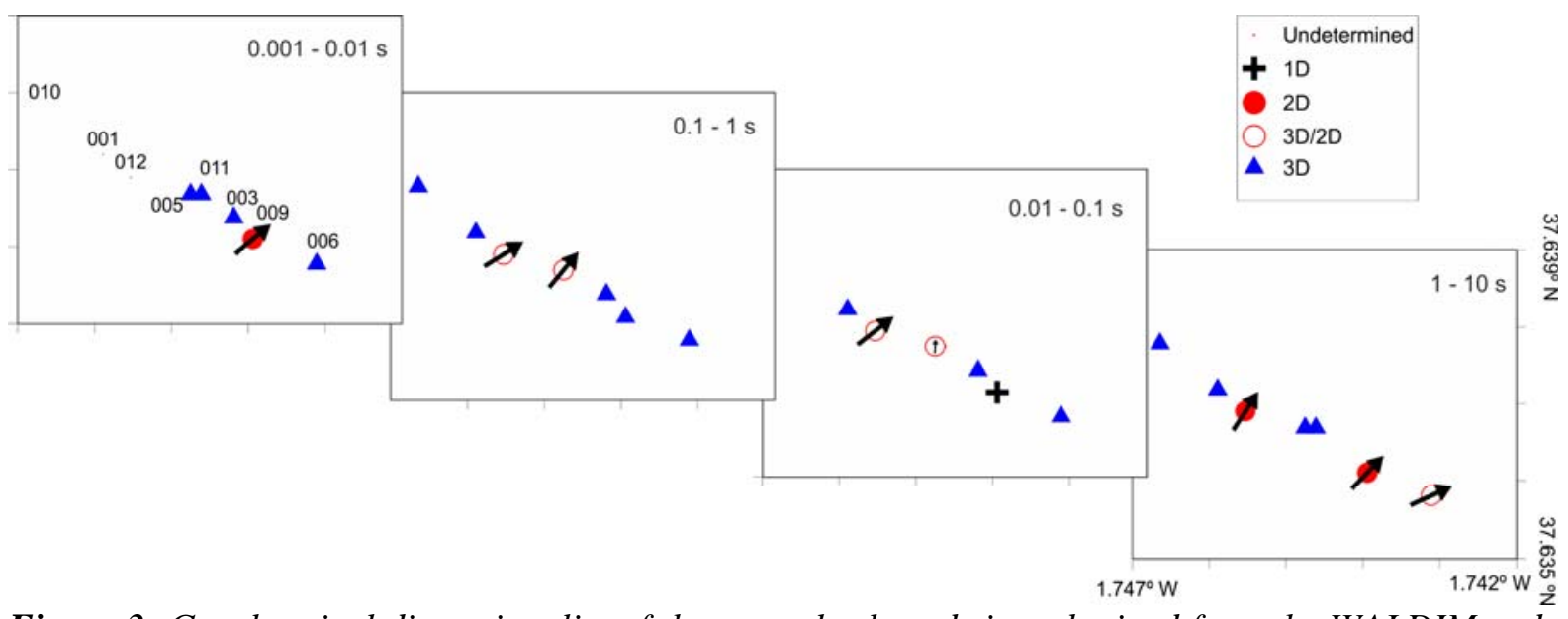

Figure 3: Geoelectrical dimensionality of the central selected sites obtained from the WALDIM code (v1.1) averaged over 4 period bands. Black arrows indicate the strike direction where the structure is $2 \mathrm{D}$ or $3 \mathrm{D} / 2 \mathrm{D}$ and their size is inversely proportional to its error.

The determinant of resistivity and phase are parameters that are invariant under rotation. However, the resistivity one can be affected by static shift. The resistivity pseudosection (figure 4, top) shows a more conductive part towards the $\mathrm{NW}$, which can be related to the materials of the fault gauge. The higher resistivity below sites 12 to 9 might be interpreted as the Quaternary materials, although the resistivity values (100 to $200 \mathrm{ohm} \cdot \mathrm{m}$ ) are not too high for this lithology and seem to be affected by static shift. A comparison with ERT results will help correcting this effect in the data. At longer periods the resistivity decreases at all sites. The phase determinant pseudosection (figure 4, bottom) is 
not affected by static shift and is inversely related to resistivity gradients. Hence, the increase of the phase towards the NW can be linked to its lower conductivity. Further inversion of the data will allow us characterising the resistivity below the Quaternary and define if the fault gauge materials continue towards the SE.

\section{Conclusions}

A magnetotelluric survey has been carried out crossing the Alhama de Murcia fault as part of a multidisciplinary project. Preliminary results show a more resistivity area, which might correspond to the Quaternary units, whereas the conductive areas might delineate the extent of the fault gauge materials. Further analysis and inversion of the data are necessary to obtain a more detailed picture of the extension and geometry below the fault zone.
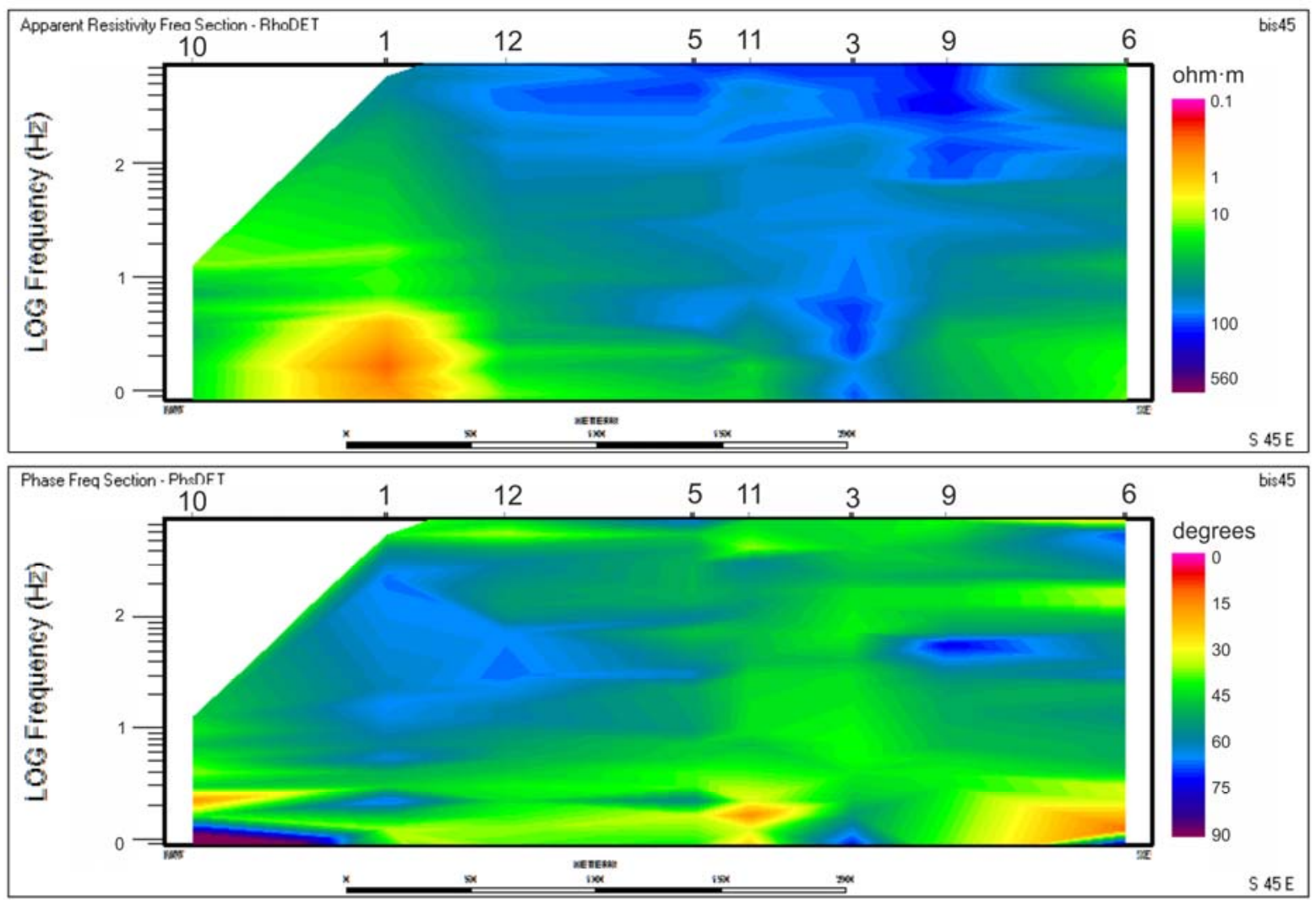

Figure 4: Pseudosections of the determinant of the resistivity (top) and phase (bottom) along the central part of the survey.

\section{Acknowledgments}

This research is part of the INGERGEOSIMA project: CGL2013-47412.

\section{References}

Martí, A., Queralt, P. and Ledo, J. [2009] WALDIM: A code for the dimensionality analysis of magnetotelluric data using the rotational invariants of the magnetotelluric tensor. Computers and Geosciences, 35, 2295-2303.

Martínez-Díaz et al. [2016] FAM-1 Borehole: first results from the scientific drilling of the Alhama de Murcia Fault, Betic Cordillera, Spain. IX Congreso Geológico de España.

Martínez-Díaz, J.J., Masana, E. and Ortuño, M. [2012] Active tectonics of the Alhama de Murcia fault, Betic Cordillera, Spain. Journal of Iberian Geology, 38 (1), 253-270.

McNeice, G. and Jones, A.G. [2001] Multisite, multifrequency tensor decomposition of magnetotelluric data, Geophysics, $66,158-173$

Moreno, X., Masana, E., Gràcia, E., Pallàs, R., Ruano, P., Coll, M., Stepancikova, P. and Santanach, P. [2007] Primeras evidencias de paleoterremotos en la falla de Carboneras: estudio paleosismológico en el segmento de La Serrata, Geogaceta 41, 135-138. 